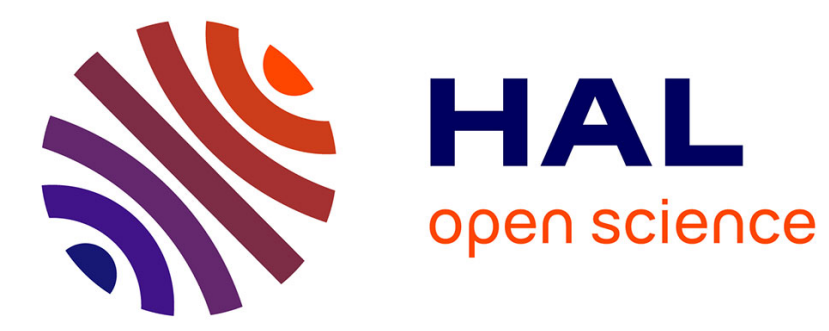

\title{
A fuzzy hedging point policy for sustainable manufacturing system
}

Sophie Hennequin, Laura Maria Ramirez Restrepo

\section{To cite this version:}

Sophie Hennequin, Laura Maria Ramirez Restrepo. A fuzzy hedging point policy for sustainable manufacturing system. International Conference On Industrial Engineering and Systems Management, Oct 2015, Seville, Spain. 10.1109/IESM.2015.7380283 . hal-01296516

\section{HAL Id: hal-01296516 https://hal.science/hal-01296516}

Submitted on 1 Apr 2016

HAL is a multi-disciplinary open access archive for the deposit and dissemination of scientific research documents, whether they are published or not. The documents may come from teaching and research institutions in France or abroad, or from public or private research centers.
L'archive ouverte pluridisciplinaire HAL, est destinée au dépôt et à la diffusion de documents scientifiques de niveau recherche, publiés ou non, émanant des établissements d'enseignement et de recherche français ou étrangers, des laboratoires publics ou privés. 


\title{
A Fuzzy Hedging Point Policy for Sustainable Manufacturing System
}

\author{
(presented at the 6th IESM Conference, October 2015, Seville, Spain) ${ }^{C} \mathrm{I}^{4} \mathrm{e}^{2} 2015$
}

\author{
Sophie Hennequin \\ Ecole Nationale d'Ingénieurs de Metz - LGIPM \\ 1, route d'Ars Laquenexy - 57078 Metz Cedex, France \\ hennequin@enim.fr
}

\author{
Laura Maria Ramirez Restrepo \\ Université de Lorraine - LGIPM \\ Ile du Saulcy - 57045 Metz Cedex, France \\ laura-maria.ramirez-restrepo@univ-lorraine.fr
}

\begin{abstract}
This paper addresses a sustainable manufacturing system, i.e. a manufacturing system on which we try to minimize all economical costs while minimizing environmental impacts and improving workforce welfare. Indeed, on one hand, this system emits pollutants and greenhouse gases during its manufacturing process. On the other hand, the social dimension i.e. the human workforce and its working conditions are also discussed and considered because of the direct and indirect costs associated. A hedging point policy is then applied and adapted to this manufacturing system by using fuzzy logic to ensure sustainability. So, a fuzzy hedging point is defined to take into account pollutant emissions and human factors in order to minimize global costs.
\end{abstract}

Keywords- environmental impacts; economical costs; workforce welfare; hedging point policy; fuzzy logic

\section{INTRODUCTION}

Since the sustainable development has been defined [1], many countries have adopted strategies to strongly encourage individuals and companies to reduce their environmental impacts [2] and act ethically. Our work registers in this context and propose to define a production control policy which not only minimizes all production costs but also considers the pollution and greenhouse gases emitted and also the social dimension to obtain sustainability. Indeed, many studies and methodologies have been proposed to include environmental impacts (especially greenhouse gases emissions). We can cite for examples [3] and [4] which give good surveys on the subject. However, the social dimension is rarely considered [5]. In this paper, we try to consider at the same time the three pillars of sustainable development to define the production control policy. However, we limit our study to the social dimension and do not include the societal responsibility of the enterprise.

The representation of human factors in industry has been the subject of numerous studies conducted by different specialists (designers, engineers, ergonomists, occupational psychologists...) whose goal is generally to find the balance between operator's capacities, whether physical, cognitive or moral, and the requirements of certain tasks [6]. Thus, the behavior of operator is defined by different factors such as external conditions, that is to say, the requirements and constraints imposed, or the nature of the task at hand, or line managers and also internal conditions (the characteristics of the individual) such as physiological, psychological and psychosocial factors such as motivation, satisfaction, confidence, fatigue, stress, and conflict [7]. More and more organizations are addressing the issue of psychological factor at work, because of the direct and indirect costs associated with this issue as higher absenteeism, lost productivity, the behavior of withdrawal, the tensions, ergonomics and musculoskeletal disorders etc. Our objective in this paper is not to clearly identify the human behavior and corresponding costs but only considering this social dimension in the definition of the proposed production policy.

The proposed production control policy is based on the well-known hedging point policy defined for the first time in [8]. In this policy, a nonnegative production surplus of parttypes should be maintained at times of excess capacity in order to hedge against future capacity shortages caused by machine failures. For the case of failure-prone manufacturing system, this policy has been shown to be optimal (see for examples [9], [10] and [11]). The hedging point policy has been adapted in [12] to take into account the pollutant emissions during the production.

In this paper, based on the results obtained in [12], we redefine the hedging point policy to include at the same time the three pillars of sustainable development. For this, we propose to use fuzzy logic which is a very interesting tool for representing human factors [13]. Indeed, fuzzy logic defined by L. Zadeh in 1965 is well suited and powerful for vague or qualitative notions [14]. Then, we propose a fuzzy hedging point policy control based on a Mamdani model [15] and empirical data in order to easily change and adapt our fuzzy system with actual and real data.

This paper is organized as follows. Section 2 addresses the considered problem and presents the sustainable manufacturing system. In section 3, our fuzzy hedging point system is detailed and explained. Numerical results are given in section 4 and a discussion is proposed. We conclude the paper and give some perspectives to our work in section 5 .

\section{SUSTAINABLE MANUFACTURING SYSTEM}

To simplify our study and the presentation, we consider a single-stage single-product manufacturing system composed 
by a machine $M$, a buffer $B$ which allows limiting losses and a constant demand by time unit denoted by $D$ (Fig. 1).

The machine can fail at any time, due to external elements such as temperature, humidity, dusts, etc., even if it is not working. When the machine fails it can not work at all, and when it is up, it can work with a production speed $u(t)$ such as $U \geq u(t) \geq 0$ where $U$ is the maximal production speed of the machine. The machine state is given by:

$$
\alpha(t)= \begin{cases}1 & \text { if the machine is up } \\ 0 & \text { if the machine is down } .\end{cases}
$$

All random variables are exponentially distributed which means that when the machine fails, the production should restart to the beginning (we have a Markov process). Mean time between failures (MTBF) is equal to $1 / f$ and mean time to repair (MTTR) is equal to $1 / r$. The failure/repair process is an independent random process.

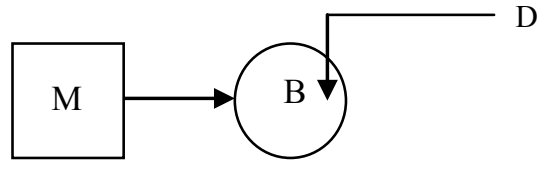

Fig. 1. Manufacturing system

We denote by $x(t)$ the inventory level given by:

$$
x(t)=\int_{0}^{t} u(s) d s-D t
$$

$x(t)$ could be negative or positive which respectively represents a backlog or a holding cost. The inventory cost $g(x)$ is then given by:

$$
g(x)= \begin{cases}c^{+} . x^{+} & \text {if } x \geq 0 \\ c^{-} . x^{-} & \text {if } x<0\end{cases}
$$

with $x+=\max (x, 0), x^{-}=\max (-x, 0)$ and where $c^{+}, c^{-}$denote the holding and backlog cost respectively $\left(c^{+}>0, c^{-}>0\right)$.

We define an environmental cost which corresponds on one hand to the use of fossil energy (then a carbon tax is applied, for example in France, in 2015, the carbon tax is equal to 7 euros by $\mathrm{CO} 2$ emitted ton) and on the other hand to the induced pollution (toxic substances, pollutants and waste). This environmental cost is denoted by $e(x(t))$ and is given by:

$$
e(y(t))=a_{e} \cdot y(t)+b_{e}
$$

where $a_{e}$ and $b_{e}$ represents respectively fixed and variable parameters of the environmental cost and $y(t)$ represents the total number of produced parts at time $t$.

$y(t)$ is equal to:

$$
y(t)=\int_{0}^{t} u(s) d s
$$

and could be expressed in function of $x(t)$ since:

$$
y(t)=x(t)+D t
$$

To take into account the social pillar of sustainable development, we also defined a hardship cost which corresponds to the machine ergonomics (i.e. cost due to musculoskeletal disorders) and to incidents and/or accidents in the manufacturing system (in this case an estimated cost). This hardship cost is denoted by $h a(y(t))$ and is given by:

$$
h a(y(t))=a_{h a} \cdot y(t)+b_{h a}
$$

where $a_{h a}$ and $b_{h a}$ represents respectively fixed and variable parameters of the hardship cost.

Similarly to the environmental cost, the hardship cost could be expressed in function of $x(t)$.

We can note that generally the inventory cost is convex and nonnegative in function of $x(t)$, and, the other costs increase in function of $x(t)$

The expected discounted cost $J(x)$, which depends on the inventory level is given by:

$$
J(x)=\lim _{T \rightarrow \infty} E\left[\int_{0}^{T} e^{-\beta s}[g(x(s))+e(x(s))+h a(x(s))] d s\right]
$$

with $\beta>0, \beta$ corresponds to the discount factor.

Hypothesis 1: $\frac{\partial J(x)}{\partial x}$ exists and is continuous in $x$, indeed $J(x)$ is continuously differentiable in $x$.

The proof for this hypothesis is similar to the proof given in [9]. The cost criterion is convex and nonnegative in function of $x(t)$ (see Figure 2).

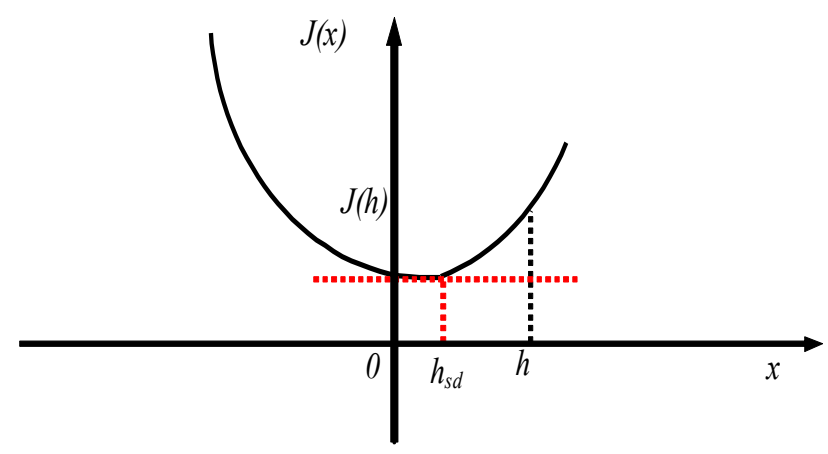

Fig. 2. Discounted cost function

Hypothesis 2: the constant demand $D$ is independent of $x(t)$ for each $t$ in $[0 ;+\infty[$.

Consequently, from equations (3), (4), (6) and (7), the discounting cost could be expressed by:

$$
\left.J(x)=\lim _{T \rightarrow \infty} E\left[\int_{0}^{T} e^{-\beta s[A}(x(s))+B . s+C\right] d s\right]
$$

with $A(x(t))$ a convex function of $x(t)$ given by the sum of $g(x(t))$ and $a_{e} \cdot x(t)$ and $a_{h a} . x(t), B$ is equal to $\left(a_{e}+a_{h a}\right) . D$ and $C$ is equal to $b_{e}+b_{h a}$. 
The chosen control policy for the machine production speed is of hedging point type. It indicates a nonnegative products surplus should be maintained in order to satisfy the demand when failures occur.

Hypothesis 3: the proposed control policy is supposed to be determinist and stationary. It is defined by:

$$
u(t)=\left\{\begin{array}{c}
0 \text { if } \alpha(t)=0 \text { or } x(t)>h_{s d} \\
D \text { if } x(t)=h_{s d} \text { and } \alpha(t)=1 \\
U \text { else }
\end{array}\right.
$$

where $h_{s d}$ corresponds to the hedging point for our sustainable manufacturing system.

This control policy satisfies the following HamiltonJacobi-Bellman equations [16]:

$$
\begin{gathered}
A(x)-D \frac{\partial J^{0}(x)}{\partial x}-(r+\beta) J^{1}(x)+r J^{0}(x)=0 \\
\inf \left\{A(x)-\beta J^{1}(x)-D \frac{\partial J^{1}(x)}{\partial x}+\right. \\
\left.u(x)\left[\frac{\partial J^{1}(x)}{\partial x}-f \frac{J^{0}(x)-J^{1}(x)}{U}\right]\right\}=0
\end{gathered}
$$

with $J^{0}(x)$ corresponds to the fact the machine is down and $J^{l}(x)$ corresponds to the fact the machine is up.

From hypothesis 3 and equations (11) and (12), the hedging point policy given by equation (10) is optimal [16].

We denote by $h$ the exact value of the hedging point which corresponds to the classical problem treated in [9]. $h$ is the optimal value when the environmental and social costs are not taken into account.

Theorem 1: The optimal hedging point for our proposed sustainable manufacturing $h_{s d}=\arg \min [J(x)]$ is given such that $h_{s d}<h$.

\section{Proof of theorem 1:}

- First, we will prove by contradiction that $h$ is different from $h_{s d}$. Suppose $h=\operatorname{argmin} \mathrm{n}[J(x)]$. Then, it implies the cost function studied by Akella and Kumar is the same as ours which is not the case. In [9], only the inventory cost is considered. Furthermore, the solution of the HJB equations is unique so $h \neq \arg \min [J(x)]=h_{s d}$.

- Then, compare the following systems with the same initial state (i.e. the same initial conditions and common parameters): i) the first one denoted by $M_{h}$ corresponds to the manufacturing system defined in [9] and ii) the second one denoted by $M_{h s d}$ corresponds to our proposed sustainable manufacturing system. From the convexity and precedent remark we have $h_{s d}<h$ [17].

Q.E.D.

From these results, we propose in this paper to estimate the value of the optimal hedging point for our proposed sustainable manufacturing system with the help of fuzzy logic. Indeed, it is difficult to calculate the exact value of this hedging point and generally, authors estimate it by simulations.

\section{FUZZY HEDGING POINT}

To achieve a sustainable manufacturing system, it is firstly important to identify and to quantify and/or qualify all impact factors for each pillar (economics, environmental and social) and then adopt sustainable development strategies.

In this paper, the objective is not to clearly quantify all these impact factors but only take them into account in the definition of the control policy. To achieve this, we propose to use fuzzy logic which is a very efficient tool when qualitative variables / notions are used without the need of employing precise mathematical analysis and functions. In our study, we define a simple Mamdani fuzzy IF-THEN rules system [15] which will allow to simply modify it if needed or in function of real data.

Our proposed fuzzy model is composed by two input variables and one output variable. The output variable corresponds to the fuzzy hedging point. It is denoted by " $h_{f u z z y}$ ". This fuzzy output will be given as a percentage of $h$, the value calculated in [9]. " $h_{f u z z y}$ " is an estimation of the exact optimal value $h_{s d}$.

We define the inputs as: "Environmental pillar" which corresponds to a percentage of the total pollution and greenhouse gases emissions, and, "Social pillar" which is based on the work done in [7] and corresponds to the operator's stresses and given by a percentage. We do not consider the third pillar which corresponds to economical aspects because it is already taken into account in the calculus of the optimal hedging point value for a classical manufacturing system, denoted in this paper by $h$.

For each fuzzy input variable, we choose to define empirically five fuzzy sets based on triangular and trapezoidal functions, denoted by "Very Low", "Low", "Medium", "High" and "Very High" see figures 3 and 4. The output variable is defined by also five fuzzy sets: "Very Small", "Small", "Mean", "Important" and "Very Important", see figure 5. 


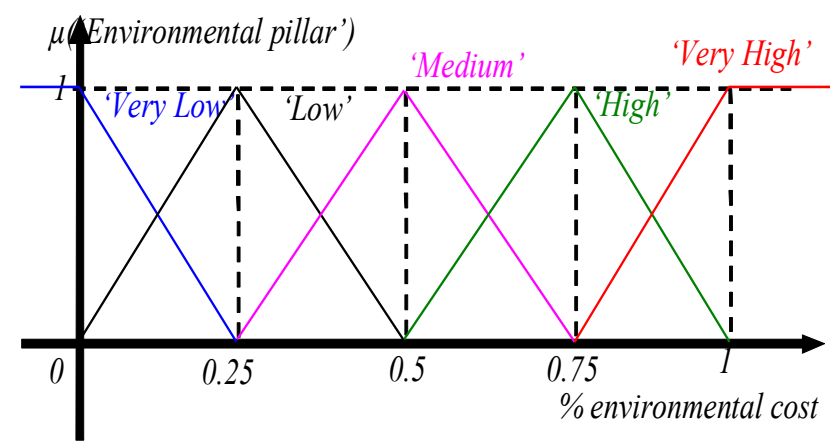

Fig. 3. "Environmental pillar" input variable.

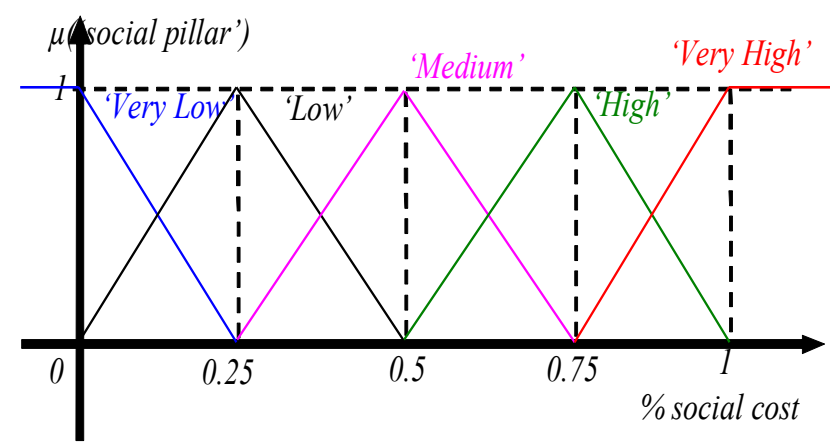

Fig. 4. "Social pillar" input variable.

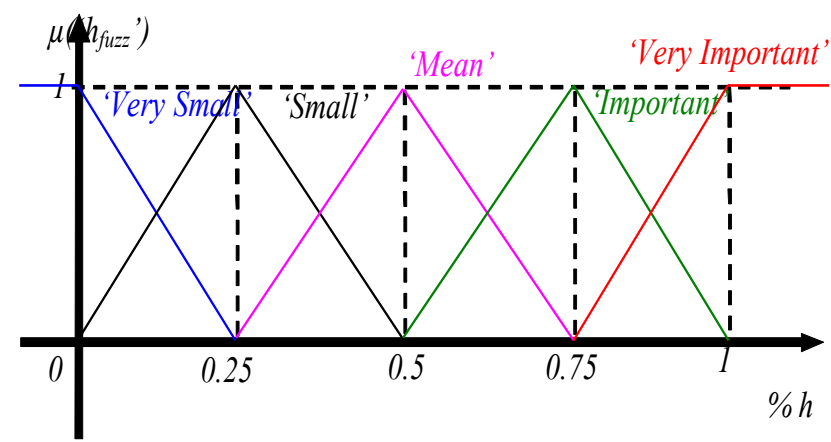

Fig. 5. Membership function of the output variable $h_{\text {fuzzy }}$.

All these fuzzy variables (inputs and output) are based on percentages, so the corresponding universes of discourse are given by: $U_{U}=\{U \mid 0 \leq K \leq 100 \%\}$ where $U$ represents the fuzzy variable. The choice of the membership functions ensures to clearly describe all the universes of discourse [15].

In this paper, the classical Mamdani's method ("Min-Max" method) is used as the inference scheme. In general, it permits to obtain good results without the need of complicated calculations, and then it is widely adopted.

For the defuzzification, which consists in the calculation of a crisp output from the obtained fuzzy output set, we choose the centroid method [15] because of its simple definition, relative little PCU time needs and the good results obtaining.

We propose, in this paper, empirical fuzzy rules based on personal assessment without given any weights to input variables or rules. This can of course easily be changed depending on the considered area in question. Our proposed fuzzy rules are based on the fact more important are the environmental and social costs, lesser the hedging point value is. Indeed, in this case, we need to produce lesser parts in order to reduce the total cost. Our fuzzy system is composed by 25 rules.

In what follows, we give two examples of rules for our proposed fuzzy system, denoted by $R^{i}$ and $R^{i+1}$ :

$$
\begin{aligned}
& R^{i}: \quad \text { If "Environmental pillar" is "Very Low" } \\
& \text { and "Social pillar" is "Very Low" } \\
& \text { Then " } h_{\text {fuzzy }} \text { is "Very Important", } \\
& R^{i+1}: \text { If "Environmental pillar" is "Very High" } \\
& \text { and "Social pillar" is "Very High" } \\
& \text { Then " } h_{\text {fuzzy }} \text { " is "Very Important". }
\end{aligned}
$$


We give in figure 6 the obtained surface for the output variable which is an approximation of the sustainable hedging point value calculated by fuzzy logic.

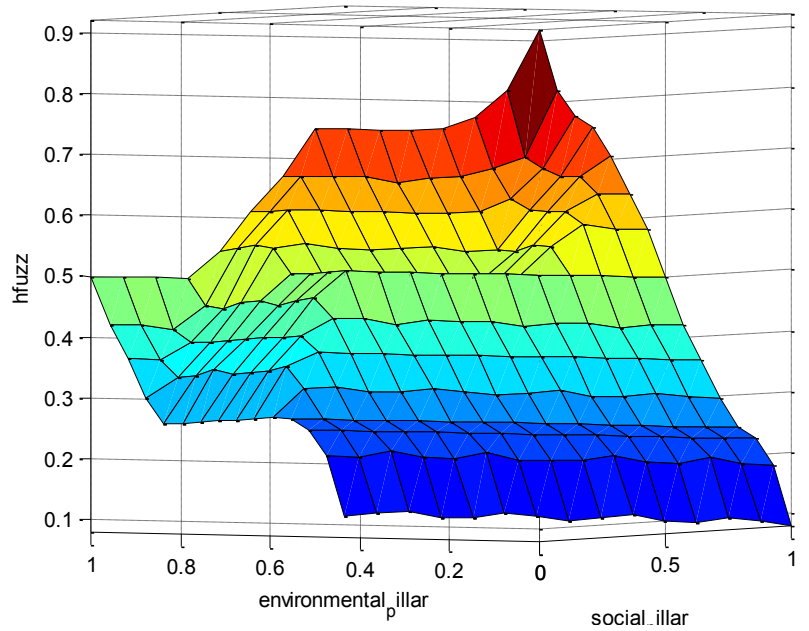

Fig. 6. Surface results of " $h_{\text {fuzzy }}$ ".

These obtained results could be easily changed according to real data or different problems.

In what follows, we propose numerical results based on our fuzzy hedging point

\section{NUMERICAL RESULTS}

We implement our fuzzy system in Matlab to simulate our model. The obtained fuzzy hedging point value is used in a discrete event system based algorithm in order to calculate the cost criterion.

The simulation parameters used are given in Table I.

\begin{tabular}{|c|c|}
\multicolumn{1}{c}{ TABLE I. } & SIMULATION PARAMETERS \\
\hline Parameter & Value \\
\hline Repair rate $(r)$ & 20 \\
\hline Failure rate $(f)$ & 3 parts by time unit \\
\hline Demand rate D & 0.6 \\
\hline Discount factor $\beta$ & 5 monetary unit by part \\
\hline Holding cost $c^{+}$ & 250 monetary unit by part \\
\hline Backlog cost $c^{-}$ & 4 parts by time unit \\
\hline Maximal production speed $\mathrm{U}$ & 1 monetary unit by part \\
\hline Variable environmental cost $a_{e}$ & 0.5 monetary unit \\
\hline Fixed environmental cost $b_{e}$ & 25 monetary unit by part \\
\hline Variable social cost $a_{h a}$ & 2 monetary unit \\
\hline Fixed social cost $b_{h a}$ & mon \\
\hline
\end{tabular}

We first compare our results with the ones obtained in [9]. They are given in Table II.

\begin{tabular}{|c|c|c|}
\hline \multicolumn{3}{|c|}{ TABLE II. COMPARISON } \\
\hline Parameter & $\begin{array}{c}\text { Classical } \\
\text { manufacturing }\end{array}$ & $\begin{array}{c}\text { Sustainable } \\
\text { manufacturing } \\
\text { system }\end{array}$ \\
\hline $\begin{array}{l}\text { Optimal hedging } \\
\text { point value }\end{array}$ & $\begin{array}{c}h=530.605 \text { parts } \\
(3.055)\end{array}$ & $\begin{array}{c}h_{s d}=486.729 \text { parts } \\
(6.613)\end{array}$ \\
\hline Optimal cost & $\begin{array}{c}J^{M h}=2677.807 \\
\text { monetary units } \\
(68.850)\end{array}$ & $\begin{array}{c}J=2858.419 \text { monetary } \\
\text { units } \\
(27.2245)\end{array}$ \\
\hline
\end{tabular}

Table II provides simulation results for the hedging point and the optimal cost for both systems. The obtained results are calculated from a discrete event based algorithm. Confidence intervals at 95 percent are also provided and numbers in parenthesis correspond to the $95 \%$ confidence half-width. These results highlight our theoretical results (see section II).

We also estimate the optimal hedging point value by using fuzzy logic and results given in [9]. The obtained results from the Fuzzy Toolbox in Matlab are then implemented in a Simulink program and obtained results are given in Figure 7, with the cost function of the classical manufacturing system [9], denoted ' $J M H$ ' given by a blue line, and the cost function of our proposed manufacturing system, denoted ' $J$ ', given by a red line. Figure 8 corresponds to a zoom of figure 7 to show the optimal value estimated by simulation.

We can remark that the obtained value of our proposed fuzzy hedging point is somehow different from the numerical results obtained with a discrete event based algorithm. However, our proposed solution is very interesting in the sense that it allows simply different kinds of adaptation such as the fact to consider all pollutants based for example on life cycle assessment or obtained results even if all the impacting elements are not quantified.

From figure 9, we can notice that the higher the discount factor, the smaller the value of the hedging point for both cost functions, with in blue line the hedging point calculated for the 
classical manufacturing system [9], denoted ' $h$ ', and in red line the hedging point calculated for our proposed manufacturing system, denoted ' $h s d$ '.

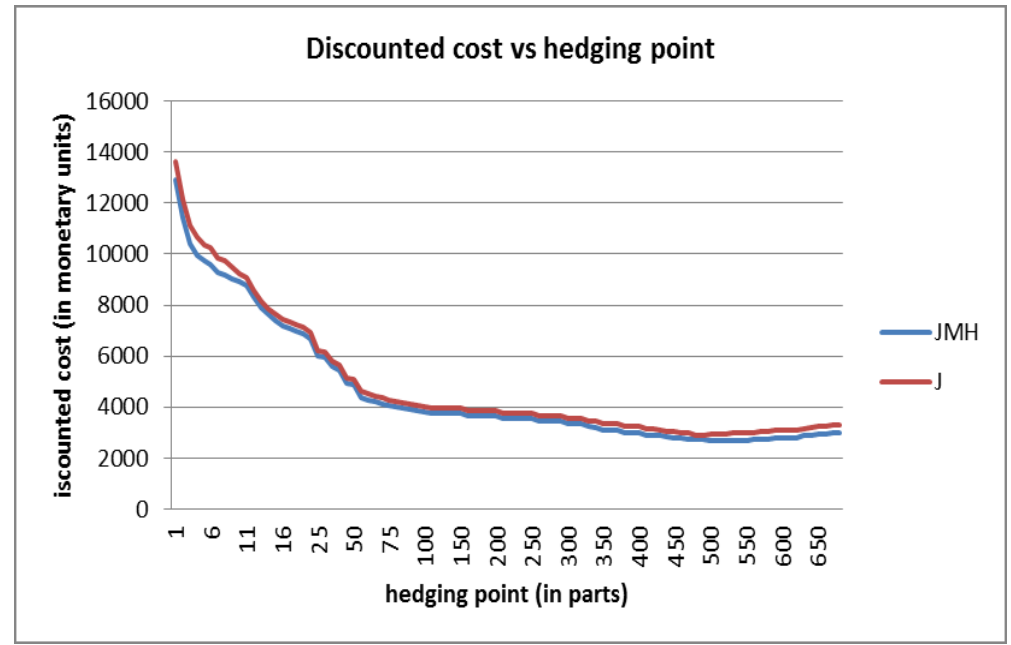

Fig. 7. Cost function calculated for the case of classical and sustainable manufacturing systems.

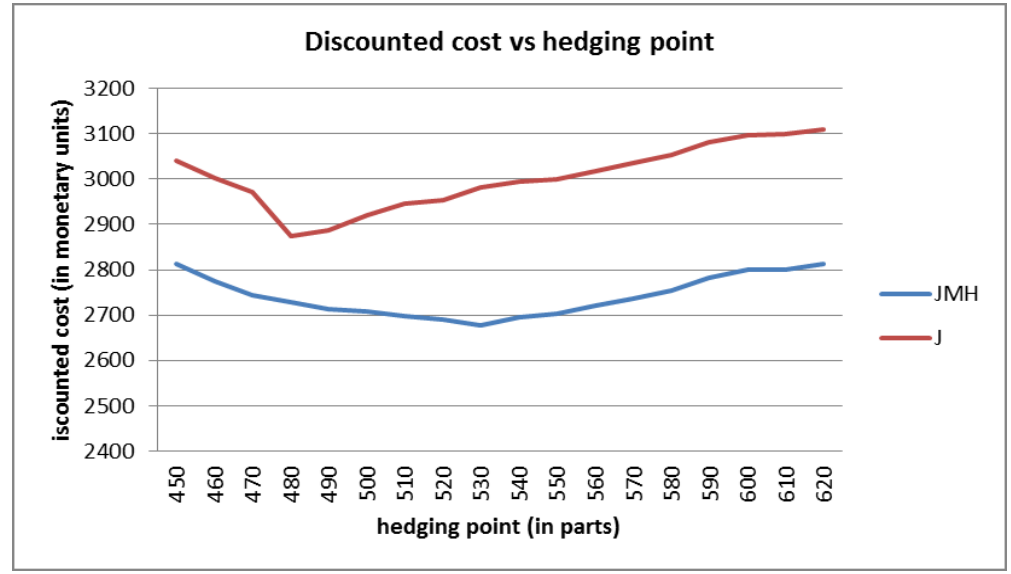

Fig. 8. Zoom of the cost function calculated for the case of classical and sustainable manufacturing systems.

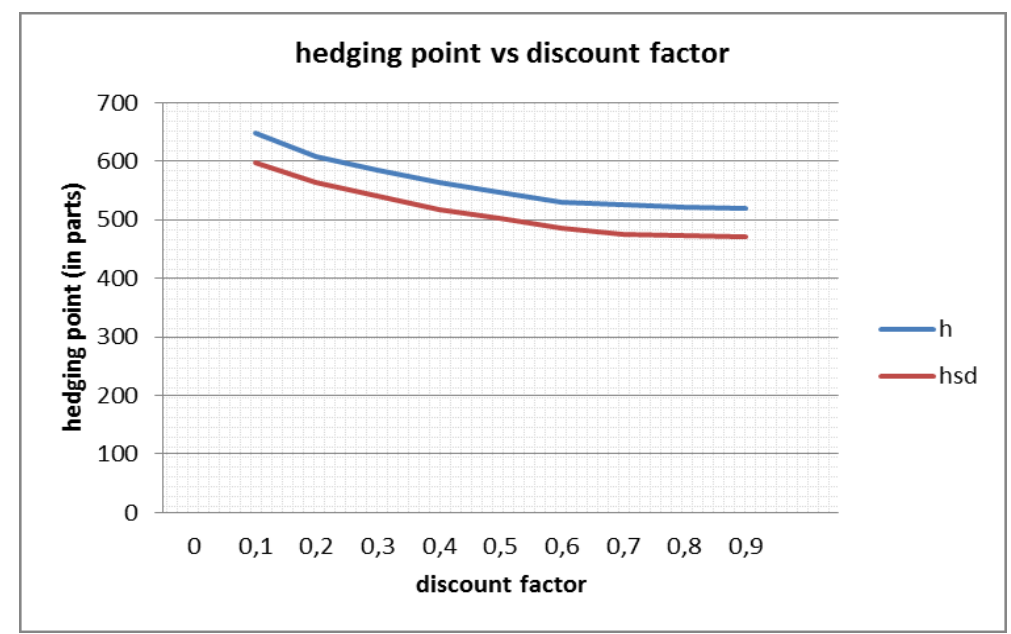

Fig. 9. Cost function versus discount factor for both cases. 


\section{CONCLUSION}

In this paper, we propose a fuzzy system to estimate the hedging point value in case of sustainable manufacturing system. By sustainable manufacturing system, we try to act to reduce the global economic costs while minimizing environmental impacts during the manufacture of parts and including social dimension, especially operators involved in manufacturing parts. Our fuzzy system is defined with empirical data in order to be simply adapted to real and industrial data or by experts.

In the future, we have to clearly identify and quantify for an industrial case study all the elements for each sustainable development pillar. Then, it is necessary to take them into account in our fuzzy system and realize a sensibility analysis to underscore key parameters that influence the results and allow managers to decide and act in case of problems. We also want to propose other control policies, such as echelon base stock, CONWIP, etc., also based on fuzzy logic. Furthermore, periodic upkeeps could be implemented to the machine to limit pollution and to improve quality and human resources strategies could be carried out to improve the operator's welfare.

\section{ACKNOWLEDGMENT}

The developed work is performed with the financial support of the Regional Council of Lorraine.

\section{REFERENCES}

[1] Report of the World Commission on Environment and Development: Our Common Future also called Bruntland Report, published in 1987 by the United Nations, http://www.un-documents.net/our-commonfuture.pdf

[2] Brown, AS “The Many Shades of Green", Mechanical Engineering 131: 2009, pp. 22-28

[3] H.C Zhang, T. C Kuo, H. Lu and S. H Huang, "Environmentally conscious design and manufacturing: a state-of-art survey", Journal of Manufacturing Systems, Vol 16(5), 1997, pp. 352-371.

[4] A. McKinnon, .M. Browne, A. Whiteing, Green logistics $-2^{\text {nd }}$ Edition Improving the environmental sustainability of logistics, Kogan Page Publishers, Ireland, 2012, the $3^{\text {rd }}$ of December .

[5] F. Székely and M. Knirsch, "Responsible Leadership and Corporate Social Responsibility: Metrics for Sustainable Performance”, European Management Journal, Vol. 23(6), 2005, pp. 628-647.

[6] S. Elkosantini, D. Gien, "Integration of human behavioral aspects in a dynamic model for a manufacturing system", International Journal of Production Research, Volume 47(10), 2009, pp. 2601-2623.

[7] S. Elkosantini, "Toward a new generic behavior model for human centered system simulation", Simulation Modelling Practice and Theory, Volume 52, march 2015, pp. 108-122.

[8] Kimemia J., Gershwin S., "an algorithm for the computer control of a flexible manufacturing system", in IIE Trans., vol.AC-15, 1982, p. 353362.

[9] Akella R., Kumar P. "optimal control of production rate in a failure prone manufacturing system" IEEE Trans.Automat. Control. vol. 31, n'. 2, 1986, p. 116-126.

[10] Song D., Sun Y., "optimal hedging point control for a failure-prone manufacturing system" International Journal of Systems Science, ,vol. $32, n^{\circ} 6,2001$, p. 681-688.
[11] Mourani I., Hennequin S., Xie X., "optimal discrete-flow of a singlestage failure-prone manufacturing system", International Conference on Decision and Control (CDC 2003), Maui, Hawai, USA.

[12] A. Ben-Salem ${ }^{\mathrm{a}}$, A. Gharbi, A. Hajji, “An environmental hedging point policy to control production rate and emissions in unreliable manufacturing systems," International Journal of Production Research, vol. 53, $\mathrm{n}^{\circ} 2,2015$, p. 435-450.

[13] S. Hennequin, G. Arango, N. Rezg, "Optimization of imperfect maintenance based on fuzzy logic", Journal of Quality in Maintenance Engineering, Volume 15, Number 4, pp 412-429, 2009.

[14] V. Novak, «Are fuzzy sets a reasonable tool for modeling vague phenomena?», Fuzzy Sets and Systems, Volume 156, Issue 3, 16 December 2005, pp. 341-348.

[15] H. Zimmermann, « Fuzzy Set. Theory and Its Applications », second, Revised Edition. Kluwer Academic Publishers. ISBN 0-7923-9075-X, 1990.

[16] M.O. Oke, "Optimal control approach to robust control of linear and non-linear systems" Mathematical Theory and Modeling, Vol. 5, n³, pp. 69-76, 2015

[17] M. A. Noor, K. I. Noor and M. U. Awan, "Generalized convexity and integral inequalities", Applied Mathematics \& Information Sciences, Vol. 9, n³, pp. 233-243, 2015. 